\title{
Entrevista com Luigi Miraglia
}

\author{
A entrevista é apresentada em duas versões: no original, em latim, e em português. \\ Por Matheus Knispel da Costa ${ }^{1}$ \\ Tradução: Felipe Augusto Neves Silva e Matheus Knispel da Costa \\ Revisão técnica: Laura Rosane Quednau ${ }^{3}$
}

Nascido em Nápoles, em 1965, Luigi Miraglia é diretor da Accademia Vivarium novum, anteriormente localizada na cidade italiana de Montella, e agora nos arredores de Roma. Empenha-se na propagação do humanismo e da cultura clássica e tornou-se um dos marcos no ensino de línguas clássicas pelo método indutivo, utilizando principalmente o método do Professor Hans Ørberg, Lingua Latina per se illustrata, para o ensino do latim, e o método Athenaze para o ensino do grego antigo.

\section{ENTREVISTA EM LATIM}

Percontationem curavit Matthaeus Knispel da Costa

\section{P.: Percontator \\ A.: Professor Aloisius Miraglia}

\section{P. Quomodo factum est ut linguae Latinae studere coeperis?}

A. Sicut ab omnibus Lycaei classici discipulis, sic etiam a me puero Latinae atque Graecae linguae opera danda erat. Equidem initio credebam fore ut antiquas illas linguas eodem modo discerem atque iam inde a prima pueritia Anglicam didiceram linguam: scilicet inter ioca arridentium, ut ait Augustinus, et blanditias nutricum. Attamen statim vanam mihi concepisse spem animadverti, cum pro linguis modo notiones grammaticas easdemque siccas atque perquam aridas, modo regulas memoria discendas, quibus exceptiones continenter accedebant quamplurimae, suis parvis discipulis magistri, licet non exigua praediti doctrina, obicere

1 Discente do Programa de Pós-Graduação em Letras Clássicas e Cristãs da Pontificia Università Salesiana, Roma, Itália.

2 Discente do curso de Letras Clássicas e Cristãs da Pontificia Università Salesiana, Roma, Itália.

3 Professora do Instituto de Letras da Universidade Federal do Rio Grande do Sul. 
consueverant. Quamobrem continuo in multas magnasque difficultates incidi ipse; non enim illas notiones atque regulas cum usu, id est cum intellegendis vertendisque scriptis, coniungere poteram. Non poteram? Immo nemo poterat, exceptis perpaucis discipulis, qui nescio quo modo ad illam docendi viam facti esse videbantur. Nimirum privatos utriusque linguae magistros conducere debuit meus pater, ne propter linguarum notitiam a magistris reprobarer neve aestivum tempus inter declinationum coniugationumque tabulas degere cogerer. Nempe per id tempus parum Latina Graecaque lingua delectabar; maxime vero eo, quod multum meae pueritiae in legendis fabulis Homericis Vergilianisque ingenti cum delectatione iam consumpseram, eaque mihi spes fuerat, ut aliquando de Ulixis Graece, de Aeneae vero erroribus Latine legerem; a qua spe me magis magisque illae docendi viae atque rationes amovebant. Inclinante vero mearum rerum condicione, factum est ut, deficiente Graecae linguae cognitione, me magister reprobaverit.

\section{P. At quomodo talibus angustiis superfuisti?}

A. Mirum quidem in modum: nonnullae enim in Neapolitano sinu sunt insulae, in quibus Prochyta eique adiuncta Vivara. Quam insulam ego, ut rerum naturae studiosissimus, comitante consobrino petivi stirpes bestiasque exploraturus. Ibi vero non modo pulcherrimas arbores mirificasque aves, verum hominem quoque nactus sum, qui ea in insula degebat. Hic vir, ut postea didici, omni doctrina instructus erat: namque naturales disciplinas, litteras philosophiamque omnem apprime callebat; quin immo et Latinam linguam perbene noverat, quoniam, per quindecim fere annos apud Iesuitas demoratus, ibi perpetuo Latine locutus erat. Cuius rei casu quodam sum mihi conscius factus: nam locum quendam Taciti acceperam a magistro in Italicum sermonem vertendum, eique rei, cum in insula Vivara essem, frustra insudabam. Meos autem labores cum conspexisset, continuo accurrit magister ille; sumptoque ex meis manibus volumine, ex tempore neque ideo cunctanter Italum reddidit Tacitum. Tantam facilitatem velut portentum quoddam miratus eum interrogavi quomodo id facere potuisset; respondit magister se Latinam linguam eo pacto didicisse, quo olim plerique. Auxilium igitur ab eo poposci ut, quemadmodum ipse didicerat, ita me Latinam linguam doceret. Ergo facilioribus textibus adhibitis gradatim Latine discebam, postulante magistro nunc ut aliis verbis lectam sententiam redderem, nunc vero ut lecti loci sensum meis verbis explicarem. Itaque brevissimo 
intervallo tantos feceram progressus, ut vel in schola omnes magistri ad unum mirarentur; rerum autem veritatis inscii adolescentis animum in causa esse credebant. Nec vero lingua Latina tantum erudiebar, sed etiam Graeca: namque postulanti mihi vias ad illum sermonem una cum Latino discendum libros obtulit nonnullos magister, inter quos mihi maxime illius Todt volumen arrisit, cui index Italice est Piccolo vocabolario metodico della lingua greca ${ }^{4}$ : est enim liber utilissimus, qui omnia verba, quae in Xenophontis Anabasi inveniuntur, continet, ea tamen ratione, ut secundum argumenta disponantur. Sic igitur ad ipsum Xenophontis opus aggressus sum, quo perlecto longe firmiorem Graecae linguae notitiam mihi comparasse videbar, ita ut, cum in Lycaeo Sophoclis Antigonen legeremus, nulla fere mihi difficultas fuerit: nam frequentissima atque creberrima verba iam mihi nota erant, modoque ex decem unam aut duas voces discere debebam, cum reliqui discipuli vix unum agnoscerent vocabulum. Brevi postea in eo, quod hic periculum maturitatis vocamus, ex Latino Senecae locum interpretatus omne punctum tulit, omniumque discipulorum optimus evasi.

P. Sane maxima tuarum rerum mutatio haec fuit; neque iam linguas Latinam atque Graecam aegre tulisse videris.

A. Eas linguas non modo non aegre ferebam, verum etiam mira quadam animi propensione novoque studio colere coepi. Intellexeram enim, auxilio illius magistri, has linguas non esse antiquorum modo hominum propria, sed pertinere ad omnes hominum aetates, quae veterum Graecorum Romanorumque tempora, usque ad tempora satis recentia, subsecutae erant. Quantum mirabar, cum philosophorum quales sunt Benedictus Spinoza et Iohannes Locke opera, quae Italice inter scholas tractabantur, re vera Latino sermone nobis esse tradita comperiebam! Illud vero me maxime movebat, quod nisi magistrum illum convenissem, totum nostrum cultum nostramque humanitatem, quibus per Graecam Latinamque linguam accedimus, numquam cognovissem, sed potius, propter inefficaces docendi rationes viasque, acerrime odissem. Tunc mihi officii munerisque conscius factus sum: etenim, quando per rectam docendi viam clavem ad cultum humanitatemque nostram acceperam, tot discipulos quotannis in cassum operam oleumque perdere pro turpissimo ducebam. Ideo mutata mente, nam antea naturali historiae in universitate studere ethologusque, quem vocant, fieri volebam,

4 B. Todt, Piccolo vocabolario metodico della lingua greca, tradotto sulla quinta edizione originale tedesca col consenso dell'autore da Achille Cosattini, Livorno, Raffaello Giusti, 1933.

Organon, Porto Alegre, v. 29, n. 56, p. 315-331, jan/jun. 2014. 
nomen litterarum classicarum facultati eo consilio dedi, ut post lauream coronam impetratam docendi rationibus discipulis subvenirem iisque facultatem cognoscendi nostra litterarum monumenta praeberem.

\section{P. Quomodo id faciendum censuisti?}

A. Statim ab impetrata in studiorum universitate laurea, quamvis iuvenis admodum essem, conventicula, seminaria, acroases per Campaniam agitare coepi, ut alios magistros certiores facerem nos posse meliorem efficacioremque in modum Latine atque Graece docere. Immo etiam magnum quendam virorum doctorum conventum anno MCMXCI familiaribus opibus usus institui, quem conventum Italice appellabatur Latino sì, ma non cosi; ludum procul dubio animadvertis et iocum in his verbis: etenim significare volebam nobis sane Latinam linguam esse docendam, mutatis tamen docendi viis rationibusque. Tunc primum nonnullos magistros congregavi, qui docendi artem tractarent. Verum labente tempore suasuque illius insulani, ut ita dicam, magistri indagare coepi quomodo optimus quisque magister, quales Guarinus Veronensis, Victorinus Feltrensis Iohannesque Coletus fuerunt, linguas litterasque antiquas in suis scholis docuissent; et ita didici XIV et XV saeculis omnino aliter quam mea aetate discipulos suos instituere consuevisse praeceptores: namque grammaticos libros, vel potius libellos inveni, qui non tam ad describendas exponendasque linguas, quam ad linguarum fundamenta discenda componebantur; quae fundamenta cum tenerent parvuli discipuli per exercitia quamplurima linguarumque usum ut ita dicam vivum (ut puta per familiaria colloquia) ad talem Latinae atque Graecae linguae notionem perveniebant, ut saepe digni esse viderentur, qui cum antiquis stilo certarent. Anno autem MCMXCVIII novum omnium gentium conventum ordinavi, qui a docendo nomen sumpsit; nec mirum: nam ex toto terrarum orbe huc in Italiam docti viri magistrique confluxerunt plurimi, qui testimonium perhiberent ceterisque illustrarent quibus docendi methodis sui discipuli bonos fructus cepissent. Maximam in famam hic doctorum conventus venit, diurnariique omnes, Italos in primis dico, verum etiam exteros, quotidie et in actis diurnis et in radiophonicis atque teleoramicis emissionibus nuntios de magistris Latine inter se loquentibus referebant. Nempe his peractis saepius itinera in multas variasque terras facienda suscepi, linguarum magistros quamplurimos conveni, Latinae Graecaeque linguae usum in scholas studiorumque universitates inducere conatus sum. Quem ad finem domum editoriam condere placuit, ut libros ad 
rem nostram pertinentes ipsi ederemus, in primis Iohannis Orberg volumen quod tunc Lingua Latina secundum naturae rationem explicata ${ }^{5}$ inscribebatur: namque eo libro Iohannes ille Orberg, ut egregius magister, aptissimas docendi rationes vel aptiores reddidit, immortale profecto opus nobis relinquens.

\section{P. Nunc vero ad Vivarium novum transeamus. Unde talis Academiae condendae consilium cepisti?}

A. Academia nostra partim, ut ex ipso nomine patet, ad praeclarum illud Cassiodori Vivarium, partim vero ad insulam Vivaram referenda est. Ea enim in insula praeter linguas Latinam Graecamque rem mirificam expertus sum, parvam scilicet hominum societatem, cuius participes, duce magistro illo, omne studium omnemque operam in humanis rebus nostrorumque temporum difficultatibus ponebant, dum communem vitam de iis rebus cogitantes atque inter sese disputantes degebant. Ad quae facienda illa insula locus aptior nullus: namque ex altis rupibus Vivariensibus nobis reliqui homines in conspectu erant, longeque melius ipsam vitam investigare atque intellegere poteramus a medio rerum omnium torrente paulisper discedentes. Talia expertus aliquid simile proponere volebam, locum videlicet ubi iuvenes non modo litterarum animique cultum sibi compararent, sed etiam illud pro officio susciperent, ut doctrinam litterasque cum vitae usu coniungerent. Ergo anno MCMXCI prima nostrae scholae statuta ita chartis mandavi, ut vere humanisticam, ut ita dicam, conderem Academiam, ubi iuvenum animi per interrogationes disputationesque ad liberum iudicium incitarentur; deterrimum enim equidem ducebam homines non iam liberum in modum res in diversas partes diiudicare, sed citius in decantatas aliorum opiniones incidere. Iis tamen temporibus nostra Academia forma erat libera, id est discipuli qui in ea deversabantur magis sua sponte suoque Marte studia provehebant, quam inter scholas, quae tunc non multae erant pro magistrorum numero. Aliquot vero post annis Gerardus Marotta causarum patronus egregiusque magister Iohannes Pugliese Carratelli me Neapolim in Vesuvinum Deversorium invitaverunt; ubi, inito colloquio, statim ad rem perventum est: omnium gentium scholam quam primum institui debere. In cuius rei argumentum narrabat Iohannes Pugliese Carratelli se honorificis laureis coronatum esse multis in studiorum universitatibus, ubi tamen eae disciplinae, quae maxime ad humanitatem faciunt, penitus neglectae

5 H.H. Ørberg, Lingua latina secundum naturae rationem explicata, Copenhagen, The Nature Method Institute, 1959.

Organon, Porto Alegre, v. 29, n. 56, p. 315-331, jan/jun. 2014. 
iacebant; ideoque oportere in harum universitatum locum sufficere renovatam quandam scholam. Quae quidem non ubilibet condenda erat, sed potissimum in meridiana Italia: namque ibi, ut est apud Brunonem illum Snell, Europaeus cultus radices egerat suas, ibi Italica illa schola philosopha, ibi Pythagoras, Parmenides, Zeno, Xenophanes, Empedocles, ad summam ii philosophi domicilium habuerant a quibus postea Socrates eiusque discipulus Plato, ut Aristotelem sileam, plurimam doctrinam hauserunt. Non igitur sine causa tota illa terra $\mu \varepsilon \gamma \alpha \dot{\alpha} \lambda \eta{ }^{E} E \lambda \lambda \dot{\alpha} \varsigma$ appellata erat; non sine causa inde Romani multum sumpserunt ad suum cultum provehendum humanitatemque corroborandam, non tandem sine causa ibi res Christiana fide atque doctrina mirum in modum augeri atque propagari coepta est. Eo ergo in loco nostra Academia fieri debebat, quo Europaeus cultus suas tres radices penitus immiserat. Quamobrem aptam nobis sedem iis in terris quaerere coepimus, primum apud Paestum Veliamque, deinde apud Herculaneum et Pompeios, postremo apud Hirpinos, ubi ad tempus mihi visum est meis facultatibus rusticas quasdam aedes conducere ibique Vivarii novi Academiam collocare. Quindecim igitur annos Montellae in oppido Campaniae commorati sumus, discipulosque a plurimis studiorum universitatibus missos suscepimus, quorum quidem studia in Vivario peracta postea in singulorum universitatibus agnoscebantur comprobabanturque. Verum quidam ex discipulis magistri efficiebantur; itaque Vivarii magistri paulatim maiores numero fiebant. Anno autem MMIX Romam etiam atque etiam incitati Lares transtulimus, in id quippe aedificium, ubi etiamnunc degimus. Magnae quidem sunt hae aedes nostraeque rei aptae, adeo ut iis consulentes, qui totum annum apud nos propter negotia manere non possunt, scholas aestivas instituerimus. Quae scholae inter Iunium Augustumque mensem recitantur, discipulique, qui iis intersunt, a primis Latinae linguae fundamentis usque ad classicos adsiduosque scriptores, quales Livius, Cicero, Vergilius atque Horatius sunt, non sine gaudio et delectatione perveniunt.

P. Mirum istud quidem, nam his temporibus antiquarum linguarum studium res taediosissima atque ab omni iucunditate abstracta esse videtur. Num ita se res habet?

A. Pro dolor ita se rem habere apparet: maxima enim rerum mutatio inter XVIII et XIX saeculum facta, altera ex parte litterarum studia sunt exquisitiorem in formam redacta: namque viri docti libros codicesque per minutias scrutantes non modo veterum auctorum scripta expurgare et 
quasi restaurare poterant, sed etiam melius aptiusque cum illis operibus hominum rerumque gestarum memoriam coniungere coeperunt; altera tamen ex parte maximum malum nobis, ut non tam litterarum quam humanitatis studiosis, exortum esse video: ea enim studiorum ratio, quae Germanice Altertumswissenschaft dicitur, homines nihil aliud docuit, nisi inter nos antiquosque nullum commercium, immo maximum esse discrimen; nos aliud, illos aliud esse; et ideo in tractandis rebus antiquis eam nobis debere esse mentem, qua et medicis cadavera dissecantibus. Novam insuper in medias res est inducta notio, quam "postulatum obiectivitatis" appellare placuit: ita omnes disciplinae sibi obiectum quoddam proponere debent, nempe a se alienum, idque exponendum per demonstrativam quandam rationem. At provincia nostra homo est, neque temere disciplina nostra humanistica nuncupata est; homines sumus, et cogitantes de hominibus qui multis ante nos saeculis fuerunt nostram, nostram causam agimus. Quapropter non demonstrativam, sed argumentativam adhibemus rationem: rhetoricam scilicet artem. Homines ad veram scientiam non per praecepta et certas atque definitas regulas umquam pervenerunt, verum per meditationem disputationemque. At sunt qui Senecae pagellas idcirco evolvant, quod in epexegetico usu vocabuli quod est "ut" operam studiumque suum ponere volunt. Digna quidem omni labore res: attamen Seneca opera sua non eo consilio nobis reliquit, ut singulorum verborum minutias perscrutaremur, sed potius ut nobis ad vitam beatam pervenire volentibus subveniret. Arida illa studiorum ratio non alia de causa maximum taedium parit, nisi quod materiem tractandam ab usu vitae omnino amovent.

\section{P. At ad reliquas scientias, id est physica, ratio illa aptissima esse videtur.}

A. Sane aptissima esse videtur: quantos enim progressus artes fecerunt et faciunt! Illud tamen Ciceronis tenendum: honos alit artes, omnesque incenduntur ad studia gloria, iacentque ea semper, quae apud quosque improbantur. Namque quo tendant isti omnium artium progressus nosmet ipsi interrogemus oportet. Num ad hominum genus tutandum, curandum, provehendum? An potius ad lucrum compendiumque faciendum? Si pecunia pro summo bono habetur, mercatoria ars ceteras sibi subigat necesse est. Ideo mirum aliquid fit, id est ut nostrae aetatis mechanici progressus sint potius humanitatis regressus. Nam susque deque feruntur homines eorumque mores, dummodo ad omnium rerum abundantiam perveniatur; commoda plura in dies habemus, facilior nostra redditur vita, nec tamen

Organon, Porto Alegre, v. 29, n. 56, p. 315-331, jan/jun. 2014. 
laetiores beatioresve nobis videmur. Bona enim et ea quae vitam beatiorem faciunt semper fere eadem fuerunt semperque erunt, neque ullo modo a novis rebus instrumentisque inveniendis pendent. Hoc per humaniores litteras proponimus, ut, qui per saecula et hominum aetates quomodo possimus bene beateque vivere quaesiverunt, eos ad colloquium convocemus, eos de aurea in omnibus rebus mediocritate servanda, de iustitia ut suum cuique tribuendo audiamus, ab iis denique aliquid tempore maius accipiamus.

P. Nihilominus extra Europam possint esse qui Europaeum, id est Graecum Latinumque cultum, propter rerum gestarum vicissitudines alienum a se ducant.

A. Difficilis quidem est haec quaestio; credo tamen me per domesticum quoddam exemplum ad eam respondere posse. Etiamnunc in Italia ea studia, quae classica appellantur, praecipue vero Latina, non parva suspicio insequitur; Fascale enim regimen, cum pro sui dominatus argumento antiquum Romanorum imperium sumpsisset hominesque ideo ad Romanarum rerum studia instigavisset, labe maculaque antiquorum cultum et humanitatem inquinavit. Abusus autem non tollit usum; antiquique scriptores per philosophiam, carmina, historiam homines magis ad virtutes colendas quam ad Fascalibus inserviendum incitavisse videntur. Ad rem nunc revertamur. Qualia et quanta coloni Europaei in Americis patraverint, luce clarius apparet. Inde quispiam, ut puta Brasilianum, argumentum sumere possit ad abiciendum una cum Europaeorum imperio eorum cultum atque humanitatem. Cultum autem, ut est apud Georgium illum Hegel, ex thesi, antithesi et synthesi constare credimus; qua de causa, ut exemplum afferam, Brasilianorum cultus et humanitas ex iis, fit quae in Brasilia iam erant, et ex iis, quae adventicia esse videantur. His in rebus difficulter pars aufertur sine totius rei detrimento. Quod quidem, ut docet Laurentius Valla in praefatione ad suos Elegantiarum libros, in Romani imperii provinciis iam factum erat: inclinante enim Romanorum potestate, gentes nationesque Romanum iugum, non sermonem deposuerunt, quoniam se Latinas litteras reicientes maximo bono privatum iri pro compertissimo habebant. Ergo ut Graecia capta ferum victorem cepit, sic etiam eae civitates resque publicae, quae exteram vim pertulerunt, feros victores capere eoque modo locupletiores fieri debent. Hoc unum denique addam, esse quosdam homines qui pro "Europaeo" "occidentalem" cultum malint. Ego autem pro iis "humanum": quando nullus est verus cultus quin et humanitas appellari possit, cum 
ad omnes homines, nullo discrimine facto, attineat. Nostrae modo aetati si studemus consequitur ut ei assuescamus. Per verum autem cultum humanitatemque in ipsa rerum temporumque mutatione ea, quae non mutantur, percipere nobis datur; indeque animos, inde vires ad nostras difficultates solvendas sumere possumus.

\section{P. Ut finem faciamus, quales discipulos ex Vivario novo evasuros speras?}

A. Nostros discipulos non scholae sed vitae parare conamur. Etenim hoc volumus, ut, potius quam studiorum universitatum cathedras, humanitatem hominisque dignitatem attingere nitantur. Bonos fortes suique officii conscios volumus cives, qui magis aliis quam sibi ipsi studeant: sic enim hominum societatem totumque mundum meliorem efficere possumus. Nostrae Academiae sunt adagia duo: alterum est profusum sapientiae semen

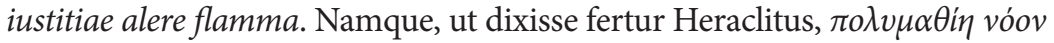
ov̉ $\delta l \delta \alpha ́ \sigma \kappa \varepsilon l$, multaque scire possumus nihil prorsus sapientes. Doctrina cum caritate est coniungenda; nonne illi, qui nazistae vocabantur, e memoria Homerica carmina recitare poterant? Quod eos non impedivit, quominus homines quamplurimos ad horrendam mortem etiam atque etiam mitterent. Alterum vero adagium illud Augustini est: nos sumus tempora; quales sumus, talia sunt tempora. Saepe enim homines idem dicentes audimus, atque ante multa saecula iam Tacitus rettulit: "saeculum est". Res ita se habere dicunt neque quidquam aliud fieri posse. Nos vero nostros discipulos eo ducere temptamus, ut animadvertant nihil aliud esse tempora nostra quam nos, quibus mutatis, tempora mutentur necesse est.

Die XV m. Ianuarii a. MMXIV

\section{ENTREVISTA EM PORTUGUÊS}

\section{E. $=$ Entrevistador \\ L. $=$ Professor Luigi Miraglia}

\section{E. Como começaste a estudar Latim?}

L. Eu devia, como todos os alunos do Liceo Classico italiano, estudar tanto latim quanto grego. No começo eu até acreditava que poderia aprender essas línguas antigas da mesma forma pela qual, desde meus primeiros Organon, Porto Alegre, v. 29, n. 56, p. 315-331, jan/jun. 2014. 
anos de vida, havia estudado inglês, ou seja, "com as brincadeiras", como diz Santo Agostinho, "e os mimos das risonhas criadas". Logo, porém, percebi ter criado uma esperança vazia, já que os professores, embora fossem dotados de grande instrução, em vez de ensinarem línguas, estavam mais acostumados a propor que seus pequenos pupilos apenas decorassem frias e áridas noções gramaticais e regras, às quais inúmeras exceções ajuntavam-se continuamente. Por essa razão, comecei a ter muitas e grandes dificuldades, pois eu não era capaz de relacionar aquelas noções e regras com o uso, para a compreensão e a tradução de textos. Eu não era capaz? $\mathrm{Na}$ verdade, ninguém era, fora aqueles pouquíssimos alunos, que, não sei como, pareciam aptos àquele método de ensinamento. Meu pai, portanto, viu-se obrigado a contratar professores particulares de latim e grego, para que eu não fosse reprovado na escola por conta dessas línguas e fosse assim forçado a passar minhas férias de verão em meio a tabelas de declinações e conjugações. Certamente durante aquele tempo o latim e o grego não me agradavam; no entanto, depois de ter passado, com enorme prazer, grande parte de minha infância lendo as histórias de Homero e Virgílio, eu tinha esperança de que um dia pudesse ler as aventuras de Odisseu em grego e as de Eneias em latim, mas aquelas formas de ensinar cada vez mais me apartavam da minha esperança. Enfim, com o piorar da minha situação, acabei sendo reprovado por não saber grego o bastante.

\section{E. Como pudeste, então, superar essas dificuldades?}

L. De um modo realmente surpreendente. No Golfo de Nápoles, entre as muitas ilhas, há a ilha de Prócida e, justa a esta, a de Vivara. Eu, um amante da natureza, fui com um primo a essa ilha, à procura de plantas e animais. Ali, porém, encontrei não só belíssimas árvores e aves maravilhosas, mas também um homem que vivia naquela ilha. Esse homem, como descobri depois, era um erudito em todos os campos, já que conhecia profundamente as ciências naturais, a literatura, a filosofia... Sabia até mesmo latim, dado que tinha passado quase quinze anos em companhia de jesuítas, com os quais sempre falava latim. Eu no entanto só tomei conhecimento disso quando, em Vivara, tentava, sem sucesso, traduzir em italiano um excerto de Tácito, que havia recebido de meu professor. Depois de ver meu sofrimento, aquele professor veio a mim imediatamente e, pegando o livro de minhas mãos, fez, de repente mas ainda assim sem recear, do Tácito latino um italiano. Admirando tamanha facilidade, como se fosse um milagre, perguntei-lhe como pudera fazer aquilo, ao que ele 
respondeu que tinha aprendido o latim pelo método que antes a maioria das pessoas utilizava. Pedi-lhe então que me ensinasse latim do mesmo jeito com que ele havia aprendido. Assim, aos poucos e com textos mais fáceis, comecei a aprender latim: meu professor ora pedia que eu dissesse em outras palavras alguma frase recém-lida, ora requeria que eu explicasse com minhas próprias palavras o trecho lido. Desse modo, depois de breve tempo, eu já tinha feito um progresso tão considerável que até mesmo na escola todos os professores admiravam-me; entretanto, como não conheciam a verdadeira razão da mudança, acreditavam que a causa fosse o meu amadurecimento. Contudo eu não estava aprendendo apenas latim, mas também grego, pois tinha perguntado àquele professor como poderia aprender essa língua junto ao latim, e ele ofereceu-me diversos livros, entre os quais me agradou especialmente o livro de Todt chamado Piccolo vocabolario metodico della lingua greca, pois é utílissimo e reúne todas as palavras da Anábase de Xenofonte, dispostas por assunto. Parti, então, para a própria obra de Xenofonte; depois que a li, sentia que havia conseguido um conhecimento de grego muito mais sólido, tanto que no Colégio já não tinha quase nenhuma dificuldade em ler Antígona, de Sófocles, uma vez que já conhecia as palavras mais frequentes e repetidas, de modo que eu tinha de aprender apenas uma ou duas a cada dez palavras, ao passo que meus colegas mal conseguiam reconhecer um vocábulo sequer. Pouco depois, naquela prova que aqui chamamos maturidade consegui nota máxima ao traduzir Sêneca em italiano, tornando-me assim o melhor de todos os alunos.

\section{E. Sem dúvida, essa foi uma grande mudança em tua vida; parece que estudar latim e grego já não te era penoso.}

L. Estudar essas línguas não me era algo penoso, pelo contrário: comecei a ocupar-me delas com admiráveis interesse e dedicação, pois, com a ajuda daquele professor, entendera que o latim e o grego não eram línguas só das pessoas da Antiguidade, mas que pertenciam a todas as épocas posteriores à dos gregos e dos romanos e até a tempos muito recentes. Como me surpreendia ao descobrir que as obras de filósofos como Baruch Espinoza e John Locke, que nas aulas eram apresentadas em italiano, tinham na verdade sido escritas em latim! Comovia-me pensar que, se eu não tivesse encontrado aquele professor, jamais teria conhecido toda a nossa cultura, da qual nos aproximamos através do latim e do grego, mas antes a teria fortemente odiado em razão dos ineficazes métodos de ensino. Tomei,

Organon, Porto Alegre, v. 29, n. 56, p. 315-331, jan/jun. 2014. 
então, consciência de um dever, de um encargo: dado que recebera a chave para alcançar a nossa cultura por um meio mais conveniente, comecei a considerar vergonhoso que, todos os anos, tantos alunos perdessem tempo sem êxito. Por isso, mudei meus planos - antes queria estudar biologia e ser etólogo - e inscrevi-me na faculdade de letras, com a intenção de, depois de formado, ajudar com renovados métodos de ensino ao alunos proporcionando-lhes a oportunidade de conhecerem os nossos monumentos literários.

\section{E. De que modo julgaste que isso devesse ser feito?}

L. Logo depois que obtive minha graduação universitária, embora ainda fosse bastante jovem, comecei a organizar na Campânia encontros, seminários, palestras, a fim de que outros professores soubessem que é possível ensinar latim e grego de uma forma mais eficiente. No ano de 1991, servindo-me dos recursos de minha família, preparei um grande congresso, sob o nome de Latino si, ma non cosi, em que podes com certeza perceber um jogo de palavras: com efeito, eu queria indicar que deveríamos sim ensinar latim, mas com uma mudança nos métodos de ensino. Pela primeira vez, então, reuni inúmeros professores, a fim de que discutissem sobre a didática. Depois, com o tempo, por causa dos conselhos daquele, digamos assim, "professor da ilha", comecei a indagar como ótimos educadores, como por exemplo Guarino de Verona, Vittorino de Feltre e John Colet, ensinavam línguas e literatura em suas escolas. Aprendi, assim, que os professores dos séculos XIV e XV costumavam instruir seus alunos de uma forma totalmente diferente da de minha época, pois encontrei livros de gramática que se prestavam menos à descrição e à exposição da língua que ao aprendizado de seus primeiros fundamentos; e, ainda, que os pequenos alunos, depois de terem aprendido aqueles fundamentos, por meio de muitos exercícios e do uso - digamos - vivo da língua (como em diálogos de amigos), alcançavam um conhecimento de latim e grego tão grande, que frequentemente pareciam dignos de fazer frente aos antigos autores no que se refere à escrita. Já no ano de 1998, organizei um novo congresso internacional, que se chamou Docere [ensinar]. De todas as partes do mundo inúmeros estudiosos e professores vieram à Itália, e deram provas dos métodos de ensino com os quais seus alunos haviam conseguido ótimos resultados. Esse congresso teve uma divulgação imensa: jornalistas, especialmente italianos, mas estrangeiros também, todos os dias nos jornais e na televisão apresentavam notícias daqueles professores 
que conversavam em latim. Posteriormente fiz muitas viagens a diversos lugares, encontrei-me com um número imenso de professores, tentei introduzir o uso de latim e grego em escolas e universidades. Pareceume por isso interessante abrir uma editora, de modo que nós mesmos pudéssemos publicar os nossos libros, principalmente o então chamado Lingua Latina secundum naturae rationem explicata, do brilhante professor Hans Ørberg, que fez de ótimos métodos de ensino algo ainda melhor, que nos transmitiu, sem dúvida alguma, como uma obra imortal.

\section{E. Passemos agora ao Vivarium novum. De onde veio a ideia de criar uma escola do gênero?}

L. A nossa academia, como se percebe já do seu nome, por uma lado faz referência ao famoso Vivarium de Cassiodoro; pelo outro, à ilha de Vivara. Nessa ilha, além de aprender latim e grego, eu pude experimentar algo maravilhoso: uma pequena comunidade cujos membros, conduzidos por aquele professor, estudavam dedicando-se completamente às questões humanas e aos problemas do nosso tempo, e isso enquanto viviam juntos pensando e conversando sobre esses assuntos. Para isso não havia lugar mais perfeito do que aquela ilha: do alto dos rochedos de Vivara avistávamos todos os demais homens, e podíamos pensar e entender a vida muito mais afastando-nos brevemente do meio da torrente das coisas. Depois dessa experiência quis propor algo parecido, um lugar onde os jovens pudessem não apenas aprender letras e filosofia, mas também sentir o dever do unir aquele conhecimento com as questões da vida. Portanto, em 1991, escrevi o primeiro estatuto da nossa escola, a fim de criar uma academia verdadeiramente humanística, onde se incitassem as jovens mentes à liberdade de pensamento através de questões e discussões; de fato, acreditávamos ser a pior das coisas o fato de que as pessoas já não julgassem as coisas independentemente como boas ou más, mas caíssem sempre nas mesmas opiniões alheias. Bem, nessa época a nossa academia era formalmente livre, ou seja, os alunos que lá viviam estudavam mais espontaneamente e por si do que entre as lições, que não eram muitas devido ao número de professores. Alguns anos depois o advogado Gerardo Marotta e o grande professor Giovanni Pugliese Carratelli chamaram-me ao hotel Vesuvio de Nápoles, onde, conversando, foi-se diretamente ao assunto: era necessária a fundação imediata de uma escola internacional. Giovanni Pugliese Carratelli contava a propósito que se tinha laureado honoris causa em muitas universidades onde, no entanto, justamente as

Organon, Porto Alegre, v. 29, n. 56, p. 315-331, jan/jun. 2014. 
disciplinas humanas pereciam devido a uma grande negligência. Por isso, uma nova escola devia substituir essas universidades. Mas essa escola não podia ser em um lugar qualquer, mas sim na Itália meridional, já que ali, como diz Bruno Snell, a cultura europeia tinha as suas raízes, ali tinhase constituído aquela escola filosófica itálica, ali habitaram Pitágoras, Parmênides, Zenão, Xenófanes, Empédocles, enfim todos os filósofos de quem posteriormente Sócrates e seu aluno Platão, para não falar de Aristóteles, muito aprenderam. Não era portanto por acaso que toda aquela região chamáva-se $\mu \varepsilon \gamma \alpha \dot{\lambda} \eta \eta$ 'E $\lambda \lambda$ àc [magna Grécia], não por acaso dali os romanos muito trouxeram para o desenvolvimento e fortalecimento da sua própria cultura, não por acaso foi ali que o cristianismo como fé e como doutrina começou a crescer e a propagar-se largamente. Por isso a nossa academia devia criar-se ali, no lugar onde a cultura europeia tinha criados profundamente as suas três raízes. Por essa razão começamos a procurar uma sede apta naquela região: primeiramente perto de Paestum e Velia, depois nos arredores de Herculano e Pompeia, e ao fim na Hirpínia, onde decici provisoriamente e com um investimento pessoal alugar uma casa de campo e ali criar a academia Vivarium novum. Passamos quinze anos nessa cidade da Campânia chamada Montella, onde recebemos muitos alunos de diversas universidades, alunos cujos estudos feitos no Vivarium reconheciam-se posteriormente nas universidades de cada um. Mas alguns dos alunos tornavam-se depois professores e, assim, o número de professores do Vivarium aumentava. Já no ano de 2009, repetidamente convidados, transferimo-nos para Roma, para o edifício onde atualmente estamos. É um edifício realmente grande e conveniente ao que propomos, de modo que, pensando em quem não pode passar um ano inteiro conosco por causa de outras ocupações, passamos a oferecer um curso de verão. Esse curso acontece entre os meses de junho e agosto, e os seus participantes partem dos elementos básicos do latim para chegar a clássicos como Lívio, Cícero, Virgílio e Horácio, e isso não sem alegria e diversão.

\section{E. Isso é estranho, já que hoje em dia as línguas antigas parecem algo extremamente tedioso, algo que está longe de toda e qualquer diversão. Não é assim?}

L. Infelizmente sabemos que é assim. Com a grande mudança ocorrida entre os séculos XVIII e XIX, por um lado os estudos literários tornaramse mais sofisticados, visto que os estudiosos, com a análise minuciosa de livros e manuscritos, puderam não apenas corrigir textos antigos, como 
também restaurá-los. Mas, por outro lado, por interessarmo-nos sim pelas letras mas mais ainda por aquela humanitas, vejo nascer-nos aí um grande mal: aquela maneira de abordar os estudos chamada em alemão Altertumswissenschaft, que ensina apenas que nós já não temos relação alguma com os antigos homens, que somos uma coisa, e eles, outra, e que, por isso, ao tratar a antiguidade, temos de nos comportar como médicos que dissecam cadáveres. Além disso introduziu-se então um novo conceito, que se chamou de postulado da objetividade: todas as disciplinas devem propor-se um objeto alheio a si e explicá-lo por meio de um método demonstrativo. Mas a nossa disciplina é o homem, e não se diz humanística por acaso; nós somos homens, e, ao pensarmos nos homens que viveram muitos séculos antes de nós, são questões nossas as que tratamos. Por isso nosso método não é demonstrativo, mas sim argumentativo, ou seja, retórico. Ninguém jamais chegou a um verdadeiro conhecimento através de normas e regras certas e definidas, mas antes através de meditação e discussão. Ainda assim há quem leia Sêneca para estudar-lhe o uso epexegético de $u t$. Sim, a coisa é digna de todo o esforço; mas Sêneca nos deixou a sua obra a fim de ajudar-nos a alcançar uma vida boa e feliz, e não para que estudássemos os pormenores de cada palavra. Essa maneira de abordar os estudos causa um tédio sem igual porque separa completamente a matéria a ser tratada da vida real.

\section{E. Mas aquele método parece perfeito às demais ciências, às ciências naturais.}

L. Parece, realmente, já que os progressos técnicos são tão grandes! É importante, contudo, lembrar-se daquela frase de Cícero: honos alit artes, omnesque incenduntur ad studia gloria, iacentque ea semper, quae apud quosque improbantur [o reconhecimento alimenta as artes: o prestígio instiga todos aos estudos, e abandona-se sempre tudo o que não se valoriza]. Precisamos perguntar-nos a que objetivam todos esses progressos técnicos. À tranquilidade, ao cuidado, à promoção de todas as pessoas? Ou, ao invés disso, ao lucro e aos interesses pessoais? Quando se acredita que o dinheiro seja a melhor das coisas, tudo necessariamente se subordina ao mercado. Acontece assim curiosamente que os progressos técnicos do nosso tempo estejam mais para regressos humanos, dado que não mais importam as pessoas e os seus atos, desde que se obtenham as maiores riquezas; temos cada vez mais comodidade, a nossa vida torna-se cada vez mais fácil, e ainda assim não nos sentimos mais alegres, pois as coisas que

Organon, Porto Alegre, v. 29, n. 56, p. 315-331, jan/jun. 2014. 
tornam a vida boa sempre foram e sempre serão praticamente as mesmas, e não dependem de maneira alguma de novas invenções e aparelhos. Nós propomos, através das litterae humaniores, que chamemos a uma conversa aqueles homens que por séculos indagaram como podemos viver bem, e os ouçamos a falar sobre a aurea mediocritas que se deve conservar em tudo, sobre a justiça como suum cuique tribuere, e, assim, recebamos deles algo maior do que o tempo.

\section{E. Apesar disso, fora da Europa pode haver pessoas a quem, por motivos históricos, a cultura europeia, ou seja greco-latina, pareça algo alheio.}

L. Essa é uma questão realmente complicada; penso contudo que posso dar-lhe uma resposta a partir de um exemplo doméstico. Ainda hoje na Itália os estudos clássicos, e em especial os estudos latinos, são alvo de não pouca desconfiança, já que o regime fascista - que tomou o antigo Império Romano como justificativa para o seu poder, estimulando as pessoas aos estudos latinos -, maculou profundamente a cultura antiga. Ainda assim, abusus non tollit usum [o abuso não tolhe o uso]; e os escritores antigos, através da filosofia, dos poemas e da história parecem incitar os homens mais à virtude do que à submissão ao fascismo. Voltemos agora ao assunto: é-nos claro como o dia aquilo que os colonizadores europeus fizeram nas Américas. Assim alguém - um brasileiro, por exemplo - poderia fazer disso uma razão para, juntamente com o domínio europeu, libertar-se daquela cultura. Nós entretanto, como Hegel, acreditamos que a cultura consta de tese, antítese e síntese; portanto, para dar um exemplo, a cultura brasileira surge do que já havia no Brasil e daquilo que possa parecer algo estrangeiro. Nessas coisas dificilmente se retira uma parte sem prejuízo do todo. Como diz Laurêncio Valla no prefácio aos seus Elegantiarum libri, algo semelhante já acontecera nas províncias do Império Romano, onde, com a queda do poder romano, os povos de origem bárbara livraram-se sim do jugo de Roma, conservando-lhe contudo a língua, pois compreendiam muito bem que o abandono daquela língua teria significado a privação de um imenso patrimônio. Portanto, da mesma maneira que Graecia capta ferum victorem cepit [a Grécia, cativa, capturou o feroz vencedor], os países vítimas de abusos estrangeiros devem capturar seus ferozes vencedores e, assim, enriquecer-se. Há uma última coisa: há quem, ao invés de cultura europeia, prefira dizer cultura ocidental. Eu não diria nenhum dos dois, mas sim cultura humana. Porque não há cultura que não se possa também chamar humanitas [humanidade, no mais alto sentido], dado que pertence 
a todos os homens, sem discriminação alguma. Se nos dedicamos apenas ao nosso tempo, acostumamo-nos a ele necessariamente. Pelo contrário, através da verdadeira cultura nos é possível perceber o que há de imutável no alternar-se do tempo e das coisas e, assim, encorajar-nos e fortalecernos a fim de resolver as nossas dificuldades.

\section{E. Para terminarmos, como esperas que sejam os alunos ao deixarem o Vivarium novum?}

L. Nós tentamos preparar nossos alunos não para a escola, mas para a vida, pois queremos que eles se esforcem não tanto a obter uma cátedra universitária, como a atingir aquela humanitas [a cultura unida à filantropia], e aquela hominis dignitas [a consciência de que ser um homem é um privilégio que comporta grandes obrigações]. Queremos cidadãos bons, enérgicos e conscientes dos seus deveres, e que pensem mais nos outros do que em si próprios: assim podemos fazer da sociedade e de todo o mundo algo melhor. A nossa Accademia tem dois provérbios. Um é: profusum sapientiae semen iustitiae alere flamma [alimentar a esparsa semente da sabedoria com a chama da justiça], já que, conforme o dito atribuído a Heráclito, $\pi o \lambda v \mu \alpha \theta i$ i vóov ov̉ $\delta \delta \delta \alpha ́ \sigma \kappa \varepsilon l$ [saber muito não educa (a mente)], e podemos saber muito sem nenhuma sabedoria. $\mathrm{O}$ conhecimento deve-se unir à caridade: não é verdade que os nazistas podiam recitar poemas homéricos de memória? E isso não os impediu de mandar repetidamente inúmeros homens a uma morte horrenda. O outro provérbio é aquela frase de S. Agostinho: nos sumus tempora; quales sumus, talia sunt tempora [nós somos os tempos, e tempos são como nós somos]. Porque ouvimos pessoas a dizer muitas vezes o mesmo que, muitos séculos atrás, já Tácito relatava: "saeculum est" [os tempos são assim]. Dizem que assim são as coisas e que nada se pode fazer. Nós, pelo contrário, tentamos fazer com que nossos alunos percebam que os tempos não são nada mais do que nós, e que, se nós mudamos, os tempos mudam por consequência.

15 de janeiro de 2014.

Organon, Porto Alegre, v. 29, n. 56, p. 315-331, jan/jun. 2014. 